\title{
Selection of Biocontrol Agents of Pink Rot Based on Efficacy and Growth Kinetics Index Rankings
}

Tugba Adiyaman, Visiting Scientist, National Center for Agricultural Utilization Research (NCAUR), United States Department of Agriculture-Agricultural Research Service (USDA-ARS0, Peoria, IL 61604 and Ege University, Science and Technology Center (EBILTEM), Izmir, Turkey; and David A. Schisler, Patricia J. Slininger, Jennifer M. Sloan, Mark A. Jackson, and Alejandro P. Rooney, NCAUR, USDA-ARS, Peoria

\begin{abstract}
Adiyaman, T., Schisler, D. A., Slininger, P. J., Sloan, J. M., Jackson, M. A., and Rooney, A. P. 2011. Selection of biocontrol agents of pink rot based on efficacy and growth kinetics index rankings. Plant Dis. 95:24-30.

The microbiota of 84 different agricultural soils were transferred to separate samples of a $\gamma$ irradiation-sterilized field soil enriched with potato periderm, and the resulting soils were assayed for biological suppressiveness to Phytophthora erythroseptica and their effect on zoospore production. The 13 most suppressive soil samples, which reduced zoospore production by 14 to $93 \%$ and disease severity on tubers by 6 to $21 \%$, were used to isolate 279 organisms. Fourteen strains that reduce pink rot infections in preliminary tests were selected for further study. Six bacterial strains that reduced the severity of disease ( $P \leq 0.05$, Fischer's protected least significant difference) in subsequent tests were identified as Bacillus simplex (three strains), Pan-

toea agglomerans, Pseudomonas koreensis, and P. lini. Relative performance indices (RPIs) for biocontrol efficacy and for each of four kinetic parameters, including total colony-forming units $\left(\mathrm{CFU}_{\max }\right)$, biomass production values $\left(\mathrm{DW}_{\max }\right)$, cell production after $8 \mathrm{~h}\left(\mathrm{OD}_{8}\right)$, and time of recovery from oxygen depletion (DT) were calculated for each strain. Overall RPI $I_{\mathrm{Eff}, \mathrm{Kin}}$ values for each strain then were calculated using strain RPI values for both efficacy $\left(\mathrm{RPI}_{\mathrm{Eff}}\right)$ and kinetics $\left(\mathrm{RPI}_{\mathrm{Kin}}\right)$. Strains with the highest $\mathrm{RPI}_{\mathrm{Eff}, \mathrm{Kin}}$ possess the best biocontrol efficacy of the strains tested and liquid culture growth characteristics that suggest commercial development potential.
\end{abstract}

Postharvest diseases of potato caused by fungal pathogens are a worldwide concern and can result in significant losses in the quality and quantity of potato tubers during storage, transport, and the marketing process (15). The causal agent of pink rot on potato, Phytophthora erythroseptica Pethybr., can cause particularly devastating disease effects on potato in storage. It was first reported as a soilborne storage disease in the United States in Maine in 1938 $(26,38)$ and, since then, has become widely distributed throughout North America as well as in most potato-growing regions around the world (35).

P. erythroseptica invades the potato plant through the roots and mainly infects tubers at the stem end through stolons previously infected by germinating oospores or zoospores. Although tubers infected with the pathogen usually are found in wet, low-lying areas of fields during harvest (2), the disease can also develop in sandy soils without excessive moisture (38). Tubers can also be infected by $P$. erythroseptica through lenticels and buds as well as wounds that occur during harvesting. High relative humidity combined with poor air circulation and cool temperatures in storage promote pathogen survival and facilitate the infection of additional tubers $(3,4,26)$. Pink rot infection is usually associated with secondary infection by anaerobic soft rot bacteria, and further losses may occur in storage due to bacterial infection of damaged tissue (38).

Most potato cultivars commonly grown in North America are susceptible to pink rot (25). A survey of North American cultivars

Corresponding author: D. Schisler, E-mail: david.schisler@ars.usda.gov

Mention of trade names or commercial products in this article is solely for the purpose of providing specific information and does not imply recommendation or endorsement by the United States Department of Agriculture.

Accepted for publication 31 August 2010.

doi:10.1094/PDIS-04-10-0284

This article is in the public domain and not copyrightable. It may be freely reprinted with customary crediting of the source. The American Phytopathological Society, 2011. with fungal disease resistance showed that over $25 \%$ of 130 cultivars released have resistance to one or more fungal diseases such as early dying, late blight, early blight, dry rot, and black scurf; however, notably, resistance to pink rot and silver scurf was absent (30).

Measures for managing pink rot in the field and in storage include planting in soils with good water drainage, crop rotation, harvesting tubers at temperatures below $18^{\circ} \mathrm{C}$, using high airflows and preventing water condensation in the tuber pile during storage, eliminating diseased tubers, and the timely application of mefenoxam-based fungicides $(20,26,30)$. Many studies suggest that mefenoxam-resistant isolates of $P$. erythroseptica are now widespread, which likely explains the failure of these chemicals to consistently control pink rot $(4,35)$ and points to the need to develop additional methods for reducing new pink rot infections in storage.

Infections by $P$. erythroseptica initiated after tuber harvest are difficult to control. Studies using phosphorous acids and various salts in furrow have shown the potential of these materials to reduce pink rot on harvested tubers $(13,20,21)$ but additional diseasereduction technologies for this purpose are still needed. With growing public interest in reducing chemical pesticide residues in food and the environment, the need to develop new pest-management technologies that reduce the use of chemical pesticides is apparent.

Several studies have been conducted on the biological control of economically important soilborne storage diseases of potato, including studies where microbial strains from various suppressive soils were found to be active against Fusarium dry rot $(27,28)$ and late blight $(11,32)$ on tubers in storage. However, research on discovering biological control agents that are specifically targeted against pink rot on stored potato tubers is limited (29).

Once putative biocontrol agents have been identified, considerable care is required to design a growth medium that is capable of achieving a high yield of effective biomass (22). The amenability of microbial strains to mass production in liquid culture is a criterion that has been suggested for determining the potential of effective strains for development as biocontrol products against plant pathogens (6) and successfully used to rank biocontrol strains relative to both growth kinetics and biocontrol efficacy upon produc- 
tion in liquid cultures of varied nutritional richness (31). Additional factors such as breadth of protection against various pathogen isolates and on multiple host cultivars have also been incorporated into the scheme to rank the commercial development potential of bacterial biocontrol strains (28). In these novel ranking schemes, strains that were not amenable to mass production in liquid culture were considered unacceptable candidates for further testing.

The purpose of this study was to obtain microbial antagonists with potential to reduce new pink rot infection of potato tubers in storage with the specific objectives of: (i) transferring microbial communities from samples of field soils to common sterile soil backgrounds and evaluating resultant communities for suppressiveness to pink rot, (ii) isolating putative antagonists from the most suppressive soils identified, and (iii) ranking the commercial development potential of the putative antagonists based on both their efficacy in reducing pink rot and their demonstration of favorable liquid culture growth kinetics in a commercially feasible medium.

\section{Materials and Methods}

Tuber source and handling. Russet Norkotah and Russet Burbank tubers obtained from the University of Wisconsin's Seed Potato Certification Program (Rhinelander, WI) were used to assay soil suppressiveness and the efficacy of bacterial isolates against $P$. erythroseptica, respectively. Tubers were stored at $5^{\circ} \mathrm{C}$ and approximately $95 \%$ relative humidity. Tubers were washed gently with distilled water, allowed to air dry, and warmed to room temperature on laboratory benches for $16 \mathrm{~h}$ prior to use in bioassays.

Production of pathogen inoculum. $P$. erythroseptica strain $\mathrm{PE}$ 02-25 was obtained from the laboratory of J. S. Miller (Miller Research LLC, Rupert, ID). Sporangia capable of liberating zoospores were produced according to the method of Miller et al. (20) as modified by Schisler et al. (29).

Assay to detect microbial communities suppressive to pink rot. Soil samples were obtained from 84 different agricultural soils, primarily recently grown to potato, in the states of Wisconsin, Washington, and Illinois. Microbial communities from these soils then were assayed for ability to suppress sporangia production and postharvest pink rot disease development incited by $P$. erythroseptica. To accomplish this, approximately $100-\mathrm{g}$ field soil samples were sieved through $2-\mathrm{mm}$ screens and stored at $4^{\circ} \mathrm{C}$ in loosely closed plastic bags until needed. Individual field soil samples then were combined with powdered, heat-sterilized potato periderm and $\gamma$ irradiation-sterilized (5 megarads minimum) sandy loam field soil (5:2:93 wt/wt/wt, respectively) in plastic bags. Soil mixtures in plastic bags were adjusted to approximately 9 to $10 \%$ moisture $[(w-d) / d]$ and shaken periodically during incubation for 1 week at $15^{\circ} \mathrm{C}$. Moisture content of preparations was confirmed using a moisture analyzer (Omni-Mark Instrument Corp., Temple, AZ). After incubation, soil mixtures were prepared for bioassay according to the method of Schisler and Slininger (27), with some modifications. Extracts of soil mixtures were produced by adding $100 \mathrm{ml}$ of distilled water to $20 \mathrm{~g}$ of mixture (containing approximately $1 \mathrm{~g}$ of the sieved field soil) in 500-ml flasks and incubating the flasks in a rotary shaker incubator (Inova 4230; New Brunswick Scientific, Edison, NJ) at $15^{\circ} \mathrm{C}$ and $250 \mathrm{rpm}$ for approximately $18 \mathrm{~h}$. After the incubation period, soil suspensions were allowed to settle on ice for $1 \mathrm{~h}$ and then the aqueous soil extract was removed.

To determine the ability of the microbial communities in soil extracts to suppress zoospore production by $P$. erythroseptica, $10 \mathrm{ml}$ of each soil extract was dispensed into petri plates containing a hyphal mat of $P$. erythroseptica $(20,29)$, and the plates were incubated in darkness at $18^{\circ} \mathrm{C}$ for 2 days. The counts of sporangia and zoospores of all flooded plates were then evaluated. Two replicates were used for each extract and approximately 16 extracts were tested per experiment, resulting in a total of six experiments.

The same extracts were also individually tested for ability to reduce pink rot disease by combining extracts and zoospores of $P$. erythroseptica. Prior to use in bioassays, each of the aqueous soil extracts was mixed with an equal volume of pathogen inoculum suspension that was adjusted with sterile soil extract to a concentration of $5 \times 10^{4}$ zoospores $\mathrm{ml}^{-1}$. This inoculum concentration incites severe disease pressure and resulted in a high level of disease severity as determined by lesion size in the bioassay used in these studies. Russet Norkotah tubers were punctured with a blunted nail to produce a wound that was $1 \mathrm{~mm}$ wide by $2 \mathrm{~mm}$ deep to simulate tubers wounded during harvesting and loading into storages. All assays were conducted by introducing $5 \mu \mathrm{l}$ of a soil extract and zoospore suspension into a wound. Controls were inoculated with a mixture of sterile soil extract, which was prepared according to the method of Schisler et al. (29), and pathogen inoculum. A strain that can reduce Fusarium dry rot, late blight, pink rot, and sprouting in storage (Enterobacter cloacae S11:T:07) (30) was used as an active antagonist control in all assays. Each tuber contained two wounds and was inoculated by a soil extract treatment or a control treatment. Six replicate tubers per potato assay treatment were arranged by repeating the entire inoculation scheme using the same randomized order of soil extracts.

Tubers were incubated in the dark at close to $100 \%$ relative humidity in trays covered by aluminum foil and enclosed in a large plastic bag for 1 week at $15^{\circ} \mathrm{C}$, the temperature at which biocontrol agents would be expected to perform in commercial tuber storage houses immediately after loading tubers into storages. The periderm was then removed from tubers and the sum of the length and width (in millimeters) of pink rot lesions surrounding the wounds was recorded. Extracts which were the most effective in reducing disease across all assays were chosen by calculating, for each experiment, the treatment effect compared with the corresponding control (percent) and then pooling data sets. For both zoospore reduction and pink rot disease experiments, data sets were subjected to analysis of variance (ANOVA) and the means separated using Fisher's protected least significant difference (FPLSD; $P \leq 0.05$ ). Extracts that reduced sporangia production or pink rot to the greatest extent compared with their respective controls were selected for isolating individual microbial strains.

Isolation of microorganisms. All of the soil extracts that were tested for suppressiveness to zoospore production and ability to reduce pink rot disease were stored immediately at $-80^{\circ} \mathrm{C}$ after combining the extract with sterile $50 \%$ glycerin at a ratio of 80:20, respectively. After the zoospore production and pink rot disease assays, data were analyzed to identify soil extracts that were the most effective in reducing zoospore production or pink rot disease compared with controls. The most suppressive soil extracts were then thawed and serial dilutions prepared in $0.004 \%$ phosphate buffer ( $\mathrm{pH} 7.2$ ) with $0.019 \% \mathrm{MgCl}_{2}$. Dilutions were spread on plates of 1-10th strength tryptic soy agar (TSA/10; Difco Laboratories, Detroit) that contained cycloheximide $\left(0.05 \mathrm{~g} \mathrm{liter}^{-1}\right)$ onequarter strength potato-dextrose agar (PDA/4, Difco Laboratories) that contained cycloheximide at $0.05 \mathrm{~g} \mathrm{liter}^{-1}$ and acidified yeast malt extract agar (YME) (yeast extract at $3.0 \mathrm{~g} \mathrm{liter}^{-1}$, malt extract at $3.0 \mathrm{~g} \mathrm{liter}^{-1}$, peptone [type III] at $5.0 \mathrm{~g} \mathrm{liter}^{-1}$, and chloramphenicol at $0.1 \mathrm{~g} \mathrm{liter}^{-1}$, acidified with $1 \mathrm{M} \mathrm{HCl}$ to $\mathrm{pH} 3.7$ after autoclaving). Additionally, separate dilutions of each extract were heat shocked for $12 \mathrm{~min}$ at $80^{\circ} \mathrm{C}$ and plated on one-fifth strength TSA (TSA/5) to select for spore-forming bacteria such as Bacillus spp. After incubation for 2 days at $28^{\circ} \mathrm{C}$, colony counts of organisms were made and several isolates of each morphologically distinct colony type from each medium were isolated in pure culture. In total, 279 bacterial isolates were streaked for purity and stored at $-80^{\circ} \mathrm{C}$ in $10 \%$ glycerol.

Assay of efficacy of bacterial isolates against $P$. erythroseptica. In all, 100 morphologically distinct isolates were produced in a semidefined complete liquid medium (SDCL) (31) and evaluated for efficacy in reducing pink rot disease. Samples of pure isolates frozen at $-80^{\circ} \mathrm{C}$ in $10 \%$ glycerol were streaked for purity onto TSA/5 (pH 6.8). After $24 \mathrm{~h}$ of incubation at $28^{\circ} \mathrm{C}$, cells were removed from the surface of colonized plates using sterile cotton swabs and used to initiate liquid medium precultures of each isolate. SDCL $(10 \mathrm{ml})$ in 50-ml Erlenmeyer flasks was inoculated to 
obtain slightly turbid suspensions (optical density of approximately 0.170 at $620 \mathrm{~nm}$ wavelength light; $A_{620}$ ) for precultures of each isolate. Precultures were then incubated in a rotary shaker incubator at $25^{\circ} \mathrm{C}$ with a throw of $2.5 \mathrm{~cm}$ and $250 \mathrm{rpm}$ for $24 \mathrm{~h}$. Precultures of each isolate were used to inoculate test cultures composed of $10 \mathrm{ml}$ of SDLC in 50-ml Erlenmeyer flasks to an optical density of $0.1 \mathrm{~A}_{620}$. Test cultures were incubated as described for precultures, harvested after $48 \mathrm{~h}$, diluted to $1 / 10$ strength, and tested in separate experiments on Russet Burbank potato tubers to evaluate the efficacy of isolates in reducing pink rot disease according to the protocol described earlier. The diluted antagonist cell concentration used varied between $10^{6}$ and $10^{9} \mathrm{CFU} \mathrm{ml}^{-1}$ depending on the cell concentration achieved by 48 -h cultures. By comparing strains using a dose that is based on a standard dilution of colonized culture broth regardless of the number of cells this represents, the efficacy of strains is compared on an identical "cost of production" basis. Total pink rot lesion size was measured and the percent disease reduction relative to the control was determined for each experiment. There were six replicate wounds inoculated for each treatment. Approximately 20 different strains were tested in each experiment. The top 14 antagonists from these experiments were then tested again in additional replicated experiments to confirm isolate efficacy against pink rot. Because experiment-treatment interactions were insignificant $(P=0.91)$, data were pooled across experiments, ANOVA was conducted, and the statistical significance of the difference in the means was assessed using FPLSD $(P$ $\leq 0.05)$.

Bacterial identifications. Six bacterial strains which reduced the severity of pink rot were identified according to the method of Rooney et al. $(23,24)$. This method is summarized as follows. To taxonomically identify each individual soil isolate, the 16S gene was sequenced (see below) and the phylogenetic position was determined relative to the type strains of closely related sequences identified by using the SeqMatch program in the Ribosomal Database Project (37). The nucleotide sequences of these type strains were subsequently downloaded from GenBank and aligned to the $16 \mathrm{~S}$ sequence of the isolate in question using the program ClustalX (36). A phylogenetic analysis was then conducted using the neighbor-joining method as implemented in the computer program MEGA4 (34) to determine the phylogenetic placement of each isolate relative to the type strains. Kimura two-parameter distances (14) were computed for all possible strain-species comparisons and used to generate phylogenetic trees with the neighbor-joining method as implemented in the computer program MEGA4 (34). The statistical reliability of internal branches was assessed from 1,500 bootstrap pseudoreplicates. If the isolate and a particular type strain clustered with a bootstrap value of $90 \%$ or greater and displayed a similarity of $97 \%$ or more with respect to their $16 \mathrm{~S}$ rRNA gene sequence divergence, then the isolate was considered to be a member of that particular species. The fragment of the $16 \mathrm{~S}$ rRNA gene that was analyzed corresponded to positions 27 to 1,387 of the Escherichia coli $16 \mathrm{~S}$ rRNA. Polymerase chain reaction (PCR) amplifications were performed with 1 unit of Amplitaq DNA Polymerase (Invitrogen Life Technologies, Carlsbad, CA), $2.5 \mathrm{mM} \mathrm{MgCl} 2,200 \mu \mathrm{M}$ dNTPs, $1.0 \mu \mathrm{M}$ each of forward and reverse oligonucleotide primers, $1 \times$ reaction buffer, and 50 to $100 \mathrm{ng}$ of template DNA. The universal oligonucleotide primers $27 \mathrm{f}$ (16) and $1387 \mathrm{r}$ (19) were used to amplify and sequence the $16 \mathrm{~S}$ rRNA gene. All PCR reactions were performed for 35 cycles, each consisting of a 30 -s denaturation step at $94^{\circ} \mathrm{C}$, a 30 -s annealing step at $54^{\circ} \mathrm{C}$, and a $1-m i n$ extension step at $72^{\circ} \mathrm{C}$. Amplification products were purified using Montage PCR Cleanup Filter Plates (Millipore, Billerica, MA). The forward and reverse strands of each fragment were sequenced using the Big Dye Kit (Applied Biosystems, Inc., Foster City, CA) on an ABI 3730 automated sequencer. The resulting DNA sequences were checked for errors through visual inspection of the chromatograms.

Determination of antagonist growth kinetics in liquid culture. Total biomass production and CFU. The productivity of the six most efficacious antagonists was evaluated based on biomass accumulation and CFU determinations. Antagonists were cultured on SDCL (31). Briefly, a basal salts medium was supplemented with vitamins, nucleic acids, tryptophane, and cysteine and contained glucose at $15 \mathrm{~g} \mathrm{liter}^{-1}$ and acid hydrolyzed casein (vitaminfree Casamino acids) at $15 \mathrm{~g} \mathrm{liter}^{-1}$. The SDCL medium contained carbon at $14 \mathrm{~g} \mathrm{liter}^{-1}$ and had a carbon/nitrogen ratio of 11:1. To obtain cultures for these analyses, 6-ml precultures of the various isolates were incubated in SDCL medium in 50-ml Erlenmeyer flasks at $25^{\circ} \mathrm{C}$ and $250 \mathrm{rpm}$ in a rotary shaker incubator. Fermentation broth from 24-h precultures was used to inoculate a 50-ml test culture in a 250-ml Erlenmeyer flask, as described previously. Test cultures were grown for 4 days at $25^{\circ} \mathrm{C}$ and $250 \mathrm{rpm}$ in a rotary shaker incubator. For biomass accumulation studies, cells were separated from the 50-ml culture broth using a prewashed, dried, and weighed 47 -mm-diameter cellulose nitrate membrane $(0.45-$ $\mu \mathrm{m}$ pore size) on a Fisherbrand vacuum filtration apparatus (Fisher Scientific Inc., Pittsburgh). After the supernatant was removed, biomass retained on the filter was washed two times with $2 \mathrm{ml}$ of deionized water. The membranes were then dried at $105^{\circ} \mathrm{C}$ in an oven for 1.5 to $2.0 \mathrm{~h}$ to a constant weight $( \pm 0.0005 \mathrm{~g})$, allowed to cool to room temperature in a desiccator, and reweighed, and the dry weight values $\left(\mathrm{DW}_{\max }\right)$ were calculated. Total $\mathrm{CFU} \mathrm{\textrm {ml } ^ { - 1 }}$ $\left(\mathrm{CFU}_{\max }\right)$ were determined by plating serial dilutions of 48 -h culture broths on TSA/5. Three replicates were used for all treatments and all experiments were repeated at least once.

Oxygen utilization during growth of antagonists in liquid culture. By monitoring the relative amount of dissolved oxygen (DO) in liquid cultures in real time, the onset of unbalanced growth can be estimated by determining when DO levels begin to recover to fully saturated levels. Strains that rapidly complete the process of converting nutrients to biomass would require less fermentation time and, therefore, would be less expensive to produce. To estimate the time when cultures had achieved near maximal cell counts, the time of recovery from maximum oxygen depletion (DT) was determined for the six pink rot antagonists. Cultures (30 $\mathrm{ml}$ each) of each of the six pink rot antagonists were grown for 48 $\mathrm{h}$ in $250-\mathrm{ml}$ shake flasks at $25^{\circ} \mathrm{C}$ and $250 \mathrm{rpm}$ in a rotary shaker incubator. A miniaturized oxygen sensor was attached on the bottom of each flask and the shake-flask holders were equipped with monitors which permitted real-time oxygen concentration measurement without stopping agitation or removing flasks from the incubator (SFR v2 shake-flask reader, PSt3 sensor; PreSens Precision Sensing GmbH, Regensburg, Germany). Oxygen concentrations were measured every $15 \mathrm{~min}$ and data transmitted via Bluetooth to a computer with SFR v2 software (PreSens Precision Sensing $\mathrm{GmbH}$ ). Oxygen concentration data were computed as "percent oxygen" based on $100 \%$ oxygen at the start of fermentation (time 0). Mean oxygen concentration values for each isolate were used to generate three separate oxygen utilization curves from three separate experiments, and DT values were determined for each isolate in each experiment.

Cell production after $8 \mathrm{~h}$. To estimate the ability of strains to rapidly produce cells in liquid culture, the optical density of test cultures was determined $8 \mathrm{~h}$ after inoculation. Liquid cultures were produced in standard shake-flask cultures as described earlier. There were three replicate flasks per experiment, experiments were conducted three times and data from repeated experiments were pooled for data analysis.

Relative performance indices. A relative performance index (RPI) for each bacterial isolate was calculated for each of the four kinetic parameters used to quantify isolate growth in liquid culture

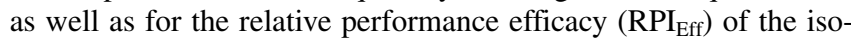
lates. Given that data values are normally distributed for the parameter tested, the value of $F=\left(X-X_{\text {avg }}\right) / s$ ranges from -2 to +2 . Here, $X$ designates a single datum value observed for a bacterial strain, and $X_{\text {avg }}$ and $s$ are the average and standard deviation, respectively, of all values observed for all bacteria for the individual parameter being tested. Using the formula RPI $=[(F+2) \times 100 / 4]$, data corresponding to each parameter type were converted to dimensionless indices with a theoretical range of 0 to 100 . Note that 
the inverted term $(2-F)$ was used in the calculation of $\mathrm{RPI}_{\mathrm{Eff}}$ and $\mathrm{RPI}_{\mathrm{DT}}$ instead of $(2+F)$, because lower disease ratings and DT values represent favorable characteristics that should, therefore, be associated with higher RPI values. The overall $\mathrm{RPI}_{\mathrm{Kin}}$ values for each bacterial isolate were obtained by subjecting the RPI values obtained for each kinetic parameter to ANOVA and mean separation using FPLSD test $(P \leq 0.05)$. RPI values for both biocontrol efficacy and kinetics for each strain were similarly analyzed to determine a commercial potential ranking of the six antagonists evaluated. Strains with the highest overall RPI when considering both efficacy and kinetics ( $\mathrm{RPI}_{\mathrm{Eff}, \mathrm{Kin}}$ ) possessed the best biocontrol efficacy of the strains tested and liquid culture growth characteristics that suggest strong commercial development potential.

\section{Results}

Isolation of microorganisms. Of the 84 samples tested, extracts of 13 soils showed indications of reducing pink rot disease severity on Russet Norkotah tubers or reducing P. erythroseptica zoospore production compared with controls and were selected as substrates for the isolation of individual microbial strains (Table 1). The soil extracts selected reduced zoospore production by as much as $93 \%$ and pink rot disease severity on tubers by as much as $21 \%$.

In total, 279 isolates of bacteria and yeast were recovered from the serial dilutions of the soil extracts (Table 1). In all, 121 isolates were recovered on PDA/4 medium, 92 isolates from TSA/10, 57 heat-tolerant isolates from TSA/5, and 9 isolates from acidified YME agar. Of these strains, 100 were selected for initial evaluation of strain efficacy in reducing new pink rot infection on stored potato tubers. Strains possessing visibly different colony morphologies were selected from dilutions of each of the 13 soil extracts. Of the 100 microbial strains, 14 reduced pink rot in preliminary tests (data not shown) and were selected for additional study.

Table 1. Activity of 13 soil extracts in reducing pink rot disease development, zoospore production by Phytophthora erythroseptica, or both

\begin{tabular}{lcc}
\hline Treatment & $\begin{array}{c}\text { Reduction of disease } \\
\text { severity }(\boldsymbol{\%})^{\mathbf{x}}\end{array}$ & $\begin{array}{c}\text { Reduction of zoospore } \\
\text { production }(\boldsymbol{\%})\end{array}$ \\
\hline 1199 - WI & $\mathrm{NE}$ & 93 \\
1261 - WI & $\mathrm{NE}$ & 86 \\
1198 - WI & $\mathrm{NE}$ & 86 \\
1248 - WI & 6 & 14 \\
1197 - WI & 21 & 43 \\
Unit 169-WG & 18 & 29 \\
Pivot 3 - WG & 26 & 76 \\
2nd Pivot - WG & $\mathrm{NE}$ & 76 \\
96-1 - WG & $\mathrm{NE}$ & 88 \\
S Garden 2- IL & $\mathrm{NE}$ & 88 \\
Duval 4- IL & 20 & 39 \\
Basil - IL & $\mathrm{NE}$ & 24 \\
S Garden 1 - IL & $\mathrm{NE}$ & 90 \\
Control & $0^{\mathrm{y}}$ & $0^{\mathrm{z}}$ \\
\hline
\end{tabular}

${ }^{x}$ Disease assays were conducted on tubers of cultivar Russet Norkotah. NE $=$ treatment not effective in reducing disease severity under assay conditions.

y Control tubers were inoculated with zoospores of P. erythroseptica $(5 \times$ $10^{4} \mathrm{ml}^{-1}$ ) suspended in an aqueous extract of $\gamma$ irradiation-sterilized (5 megarads minimum) sandy loam field soil.

${ }^{\mathrm{z}}$ An aqueous extract of $\gamma$ irradiation-sterilized (5 megarads minimum) sandy loam field soil was used to stimulate zoosporangium production by P. erythroseptica.
Isolate efficacy against $\boldsymbol{P}$. erythroseptica and relative performance indices. The 14 putative antagonists that reduced pink rot disease in preliminary assays were tested in two replicated experiments. Because experiment-treatment interactions were not statistically significant $(P=0.91)$, data were pooled across experiments and ANOVA conducted. Compared with the control tubers inoculated with $P$. erythroseptica, 6 of the 14 bacterial strains reduced disease $(P \leq 0.05$, FPLSD) (Table 2). Enterobacter cloacae S11:T07 (NRRL B-21050), which can reduce pink rot in storage, was not effective in reducing new pink rot infections under the experimental conditions of the present study. Bacillus simplex strains $03 \mathrm{WN} 13,03 \mathrm{WN} 23$, and $03 \mathrm{WN} 25$ reduced pink rot lesion size by 30,27 , and $32 \%$, respectively, while Pantoea agglomerans 10IL31 and Pseudomonas lini 13IL01 reduced lesion size by 33 and 26\%, respectively. Though B. cereus strain 03WN09 reduced pink rot disease development by $28 \%$, the strain was eliminated from further consideration because some strains of this species have been associated with causing illness in humans (8). Therefore, strain 10IL21, which was the next best strain in reducing disease after the six strains that were initially selected ( $24 \%$ reduction in severity versus the control), was included with the other five antagonistic strains for further evaluation and kinetic analyses. An RPI was calculated based on the efficacy of each of six bacterial antagonists assayed against Phytophthora erythroseptica on cv. Russet Burbank (Table 3). The most effective isolates in reducing pink rot were 10IL31 and 03WN25, which allowed 39 and 39.4 $\mathrm{mm}$ of diseased tissue, respectively, compared with an average of $58.4 \mathrm{~mm}$ for control tubers inoculated with the pathogen alone (Table 3). The six antagonists were similarly effective in reducing pink rot, as shown by similar $\mathrm{RPI}_{\text {Eff }}$ values. The six antagonists originated from one of three soil extracts, all of which were effective in reducing zoospore production by $85 \%$ or more (Tables 1 and 2).

Bacterial identifications. Selected microbial strains that significantly inhibited disease development incited by $P$. erythroseptica were identified as B. simplex (three isolates), Pseudomonas koreensis, $P$. lini, and Pantoea agglomerans (Table 2). The six strains were deposited in the ARS Culture Collection (NRRL) [http://nrrl.ncaur.usda.gov].

Antagonist growth kinetics in liquid culture and relative performance indices. The liquid culture kinetic performance of the six antagonists varied considerably, as seen in the means (Table 4) and RPI analysis of each of the four kinetic parameters tested (Table $5, P \leq 0.05$, FPLSD). B. simplex strains $03 \mathrm{WN} 13$ and $03 \mathrm{WN} 23$ had the highest biomass production value $\left(\mathrm{DW}_{\max }\right)$ of the six strains and were significantly more productive than the other four strains tested based on RPI analysis (Table 5, $P \leq 0.05$, FPLSD). Strains 10IL21, 10IL31, and 13IL01 (Pseudomonas koreensis, Pantoea agglomerans, and Pseudomonas lini respectively) produced more $\mathrm{CFU} \mathrm{ml} \mathrm{m}^{-1}$ in liquid culture than the other three strains (Table 4), with strain 10IL21 producing more CFU ml ${ }^{-1}$ than any other strain (Table $4, P \leq 0.05$, FPLSD). The ranks of the antagonists for these two parameters were not always closely aligned. For example, strain 10IL21 ranked first in CFU/ml production but sixth in biomass production ( $\mathrm{DW}_{\max }$ ) (Tables 4 and 5). Data on the time of culture medium recovery from DT (and onset of unbalanced growth) showed that the three Bacillus strains 03WN13, 03WN23, and 03WN25 and Pantoea agglomerans strain 10IL31 had the lowest DT values (Table 4; Fig. 1), indicating that these strains

Table 2. Identification of bacterial strains that reduce pink rot disease in Russet Burbank tubers

\begin{tabular}{|c|c|c|c|}
\hline Strain & NRRL accession no. ${ }^{\mathrm{z}}$ & Identification & Soil extract of strain origin \\
\hline 03WN13 & B-59398 & Bacillus simplex & $1198-\mathrm{WI}$ \\
\hline $03 \mathrm{WN} 23$ & B-59399 & Bacillus simplex & $1198-\mathrm{WI}$ \\
\hline $03 \mathrm{WN} 25$ & B-59400 & Bacillus simplex & $1198-\mathrm{WI}$ \\
\hline 10IL21 & B-59401 & Pseudomonas koreensis & S Garden 2 - IL \\
\hline 10IL31 & B-59402 & Pantoea agglomerans & S Garden 2 - IL \\
\hline 13IL01 & B-59404 & Pseudomonas lini & S Garden 1 - IL \\
\hline
\end{tabular}

z Agricultural Research Service Culture Collection (NRR1), National Center for Agricultural Utilization Research, Peoria, IL. 
rapidly exhausted one or more nutrients critical to growth in liquid culture. The DT RPI value for strain 10IL31 was higher than any other except strain $03 \mathrm{WN13}$ (Table $5, P \leq 0.05$, FPLSD). The results of cell production after $8 \mathrm{~h}\left(\mathrm{OD}_{8}\right)$ for the six strains generally exhibited the same trends as the $\mathrm{DW}_{\text {max }}$ data (Table 4). B. simplex strains $03 \mathrm{WN} 13$ and $03 \mathrm{WN} 23$ obtained the two highest $\mathrm{OD}_{8}$ values (Table 5) and their associated RPI values were higher than all but one of the other four strains tested (Table 5, $P \leq 0.05$, FPLSD). Because no strain exhibited consistently high performance across all of the kinetic parameters measured, overall $\mathrm{RPI}_{\mathrm{Kin}}$ values did not differ significantly (Table $5, P \leq 0.05$, FPLSD). Strain $03 \mathrm{WN} 13$ had the highest ranking overall $\mathrm{RPI}_{\mathrm{Kin}}$ value of 64.1

Table 3. Comparison of relative performance indices for efficacy ( $\left.\mathrm{RPI}_{\mathrm{Eff}}\right)$ and their rank for six bacterial antagonists assayed against Phytophthora erythroseptica on cv. Russet Burbank

\begin{tabular}{lcc}
\hline Strain & $\begin{array}{c}\text { Diseased tissue } \\
(\mathbf{m m})^{\mathbf{y}}\end{array}$ & RPI $_{\text {Eff }}(\mathbf{r a n k})^{\mathbf{z}}$ \\
\hline 03WN13 & $40.9^{*}$ & $51.0(3) \mathrm{A}$ \\
03WN23 & $42.8^{*}$ & $49.1(4) \mathrm{A}$ \\
03WN25 & $39.4^{*}$ & $52.1(1) \mathrm{A}$ \\
10IL21 & 44.5 & $47.9(6) \mathrm{A}$ \\
10IL31 & $39.0^{*}$ & $51.4(2) \mathrm{A}$ \\
13IL01 & $43.4^{*}$ & $48.4(5) \mathrm{A}$ \\
Control & 58.4 & NA \\
\hline
\end{tabular}

y Values followed by an asterisk $(*)$ are significantly different from the control $(P \leq 0.05$, Fisher's protected least significant difference [FPLSD]).

${ }^{\mathrm{z}}$ Rank of each RPI value mean is presented parenthetically. Within the column, values followed by unlike letters are significantly different $(P \leq$ 0.05, FPLSD); NA = not applicable.

Table 4. Performance of six antagonists of pink rot for each of the four kinetic parameters evaluated

\begin{tabular}{|c|c|c|c|c|}
\hline Strain & $\begin{array}{c}\mathrm{CFU}_{\text {max }} \\
(\log 10)^{\mathrm{w}}\end{array}$ & $\underset{(g)^{\mathbf{x}}}{\mathbf{D W}_{\text {max }}}$ & $\underset{(\text { min)y }}{\text { DT }}$ & $\begin{array}{c}\mathrm{OD}_{8} \\
(620 \mathrm{~nm})^{\mathrm{z}}\end{array}$ \\
\hline $03 \mathrm{WN} 13$ & 8.2 & $8.9 \mathrm{E}-03$ & 644 & 6.7 \\
\hline $03 \mathrm{WN} 23$ & 6.5 & $8.5 \mathrm{E}-03$ & 681 & 4.5 \\
\hline $03 \mathrm{WN} 25$ & 8.6 & 7.3E-03 & 695 & 1.4 \\
\hline 10IL21 & 10.4 & $4.8 \mathrm{E}-03$ & 1,364 & 2.6 \\
\hline 10IL31 & 9.7 & $5.3 \mathrm{E}-03$ & 562 & 5.6 \\
\hline 13IL01 & 10.0 & 7.3E-03 & 940 & 2.6 \\
\hline
\end{tabular}

${ }^{\mathrm{w}} \log$ base 10 of the CFU of the isolate obtained per milliliter of a $48-\mathrm{h}$ liquid culture.

${ }^{\mathrm{x}}$ Total biomass production values of the isolate obtained per milliliter of a 48-h liquid culture.

$y$ Time of the initiation of the recovery of dissolved oxygen values from near zero during the liquid culture production of the antagonist isolates. Recovery of oxygen values from near zero is indicative of near depletion of one or more nutrients in culture broths and associated marked reductions in cell growth rates.

${ }^{\mathrm{z}}$ Optical density of 8-h test cultures of each antagonist isolate. while strain 10IL21 had the lowest ranking overall $\mathrm{RPI}_{\mathrm{Kin}}$ value of 35.9 (Table 5).

Ranking of strain potential for development as a pink rot biological control agent. Overall $\mathrm{RPI}_{\mathrm{Eff}, \mathrm{Kin}}$ values were calculated by averaging $\mathrm{RPI}_{\mathrm{Eff}}$ and $\mathrm{RPI}_{\mathrm{Kin}}$ values. Values ranged from 57.6 to 48.8 for strains $03 \mathrm{WN13}$ and 13IL01, respectively (Table 6) but did not differ statistically ( $P \leq 0.05$, FPLSD). Based on the ranking of the strains $\mathrm{RPI}_{\mathrm{Eff}, \mathrm{Kin}}$ values, strains $B$. simplex $03 \mathrm{WM} 13$ and $P$. agglomerans 10IL31 possess the best combination of efficacy and desirable liquid culture growth kinetics of the six strains studied.

\section{Discussion}

Research on discovering and developing biological control agents has received considerable attention over the last 30 years but this work has not resulted in large numbers of commercially available biological control products for reducing plant diseases. One reason for this is that the selection of putative antagonists has been done empirically in many studies by isolating bacteria and fungi from soil and plant surfaces and selecting for further study those microorganisms which caused zones of inhibition on culture plates (5). Recently, a variety of strategies and approaches have been suggested for increasing success in isolating microbial antagonists with potential for development as biological control agents $(9,27,31,32)$. The selection of putative antagonists from pathogen-suppressive soils is one example of this type of approach. In the present effort to isolate putative antagonists of pink rot, we used this technique to recover 279 isolates of bacteria and yeast from 13 of the most suppressive of 84 soil samples assayed. Ultimately, six isolates were selected based on their efficacy in reducing pink rot in storage. Interestingly, the top six antagonist strains in reducing new pink rot infection were recovered from only three different soil extracts, all of which reduced zoospore production by at least $85 \%$ (Tables 1 and 2). Individual antagonists would need to be evaluated for their ability to reduce zoospore production before a link between mechanisms of reducing zoospore production and reducing zoospore infection success could be postulated. Compared with the control tubers inoculated with Phytophthora erythroseptica, the six bacterial strains reduced disease by 26 to $33 \%$ and all six antagonists were similarly effective in reducing pink rot, as shown by similar $\mathrm{RPI}_{\mathrm{Eff}}$ values (Table 3). Efficacy of bacterial strains isolated in this study was better than that of biological control strain E. cloacae S11:T:07 (29) when all strains were tested in the present study using fully grown culture broths that were diluted to the same extent. Though Schisler et al. (29) investigated the effectiveness of S11:T:07 and nine other bacterial strains against pink rot (P. erythroseptica), this study is the first reported investigation designed to specifically isolate novel antagonists of pink rot.

Three of six strains effective in reducing the size of lesions incited by $P$. erythroseptica were identified as B. simplex (Table 2). These strains significantly reduced pink rot severity when tested at concentrations one order of magnitude lower than found in fullstrength culture broths (Table 3). Strains of B. simplex have been

Table 5. Comparison of the relative performance indices (RPIs) for several different growth kinetic parameters determined for each of six bacterial antagonists and the overall RPI kinetics value ${ }^{\mathrm{x}}$

\begin{tabular}{|c|c|c|c|c|c|}
\hline \multirow[b]{2}{*}{ Strain } & \multicolumn{4}{|c|}{ RPI parameter ${ }^{y}$} & \multirow[b]{2}{*}{$\mathbf{R P I}_{\mathbf{K i n}^{2}}{ }^{2}$} \\
\hline & $\mathrm{CFU}_{\max }$ & DW $_{\text {max }}$ & DT & $\mathrm{OD}_{8}$ & \\
\hline $03 \mathrm{WN} 13$ & $33.9(5) \mathrm{E}$ & 76.9 (1) A & $63.8(2) \mathrm{AB}$ & 82.1 (1) A & 64.1 (1) A \\
\hline $03 \mathrm{WN} 23$ & 6.7 (6) F & $72.6(2) \mathrm{A}$ & 60.2 (4) B & 71.7 (2) A & $52.8(3) \mathrm{A}$ \\
\hline $03 \mathrm{WN} 25$ & 41.8 (4) D & 54.5 (3) B & 60.4 (3) B & 39.9 (4) B & 49.1 (5) A \\
\hline 10IL21 & 77.5 (1) A & 22.3 (6) C & $4.4(6) \mathrm{D}$ & 39.5 (5) B & 35.9 (6) A \\
\hline 10IL31 & 64.4 (3) C & 23.7 (5) $\mathrm{C}$ & 71.4 (1) A & $54.4(3) \mathrm{AB}$ & $53.5(2) \mathrm{A}$ \\
\hline 13IL01 & 69.9 (2) B & 51.3 (4) B & 39.7 (5) C & 35.9 (6) B & 49.2 (4) $\mathrm{A}$ \\
\hline
\end{tabular}

${ }^{\mathrm{x}}$ Mean RPI values are presented. The rank of each RPI value is presented parenthetically. Within a column, values followed by unlike letters are significantly different $(P \leq 0.05$, Fisher's protected least significant difference).

${ }^{y} \mathrm{CFU}_{\max }=\mathrm{CFU}$ of the isolate obtained per milliliter of a 48 -h liquid culture, $\mathrm{DW}_{\max }=$ total biomass production values of the isolate obtained per milliliter of a 48-h liquid culture, DT = time of the initiation of the recovery of dissolved oxygen values from near zero during the liquid culture production of the antagonist isolates, and $\mathrm{OD}_{8}=$ optical density of 8-h test cultures of each antagonist isolate.

${ }^{\text {z }}$ Overall RPI values for kinetics. 
linked specifically with mycorrhizal associations, and mycorrhizae can reduce the extent of root disease (17); however, this is the first report, to our knowledge, of the use of this species to reduce plant disease. Pantoea agglomerans strain 10IL31 also reduced the size of pink rot lesions (Table 3). Other strains of P. agglomerans have shown promise as biocontrol agents against a variety of bacterial and fungal plant diseases in biocontrol literature $(1,7,18,33)$. Strains 13IL01 and 10IL21 (Pseudomonas lini and P. koreensis, respectively) scored the lowest RPI values for efficacy though 13IL01 still significantly reduced pink rot disease (Table 3). A strain of $P$. koreensis has been shown to reduce disease caused by Pythium ultimum on tomato, and biosurfactants produced by the strain were also shown to reduce disease (12). Further studies are needed but it is reasonable to expect that the level of disease reduction demonstrated by diluted culture broths of strains in the current study will be improved upon by optimizing the production medium to produce higher quantities of inoculum with enhanced efficacy (29).

As a next step in selecting promising biological control candidates, we evaluated the growth characteristics, in liquid culture, of the six putative antagonists. Because a rapidly achieved high yield of biomass with cost-effective production is critical for the commercial success of a biological control agent, our selection of isolates was based on evaluating the ability of a strain to rapidly produce cells after inoculation $\left(\mathrm{OD}_{8}\right)$; rapidly reach near-maximum cell counts, as demonstrated by cultures that quickly reached a stage of unbalanced growth with concomitant recover from DT; and produce high yields of biomass, which was indicated by high $\mathrm{CFU} \mathrm{m} \mathrm{m}^{-1}\left(\mathrm{CFU}_{\max }\right)$ and biomass $\left(\mathrm{DW}_{\max }\right)$ values in a representative liquid medium.

During the growth of bacterial strains in shake flasks, DO levels are less than maximal during periods of rapid cell growth and reach near maximal levels as one or more nutrients are depleted, resulting in unbalanced growth, cell growth rates that are near zero, and the indication that the culture has reached near-maximal cell numbers. Low DT values indicate that a strain rapidly reached unbalanced growth and, therefore, near-maximal cell counts. The depletion of nitrogen, carbon, or both in the medium would be one possible explanation for the end of rapid cell growth in culture and, concomitantly, recovery of DO levels from near zero to saturation as cell respiration rates slowed. Due to the accumulation of heat during bacterial growth in deep-tank fermenters, considerable cooling and associated costs are required to maintain temperatures of 20 to $30^{\circ} \mathrm{C}$ in an industrial bioreactor. Therefore, developing strains that rapidly produce high quantities of biomass should reduce utility expenses, one of the highest operating costs associated with using commercial bioreactors.

When grown in the selected liquid medium, B. simplex strains $03 \mathrm{WN} 13,03 \mathrm{WN} 23$, and $03 \mathrm{WN} 25$ as well as Pseudomonas lini 13IL01 achieved the highest biomass value $\left(\mathrm{DW}_{\max }\right)$ of the six candidates, yet strain 03WN23 produced the lowest $\mathrm{CFU}\left(\mathrm{CFU}_{\max }\right)$ (Table 5). On the other hand, P. koreensis 10IL21 exhibited the highest $\mathrm{CFU}_{\max }$ but the lowest $\mathrm{DW}_{\max }$ and the longest time before DO recovery (DT). Hence, this strain, which also ranked as the

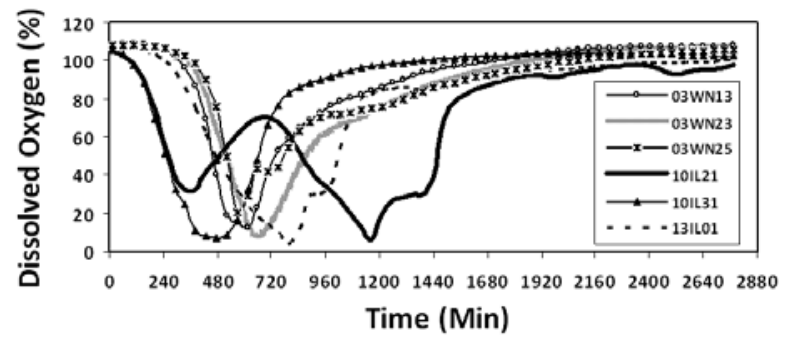

Fig. 1. Oxygen consumption by six bacterial antagonists of pink rot grown in shakeflask liquid culture for $48 \mathrm{~h}$. Oxygen sensors in flasks enabled real-time monitoring of the percentage of dissolved oxygen present in liquid broths. Data presented were used to calculate the time when isolate culture broths commenced recovery from oxygen depletion. least efficacious against Phytophthora erythroseptica (Table 3), scored the lowest overall $\mathrm{RPI}_{\mathrm{Eff}, \mathrm{Kin}}$. All of the B. simplex strains (03WN13, 03WN23, and 03WN25) and Pantoea agglomerans 10IL31 ranked as the top four strains for $\mathrm{RPI}_{\mathrm{DT}}$ and $\mathrm{RPI}_{\mathrm{OD} 8}$ (Table 5). Interestingly, $B$. simplex strain $03 \mathrm{WN} 23$ ranked last in $\mathrm{CFU}_{\max }$ despite ranking second in $\mathrm{DW}_{\max }$, perhaps due to the tendency of the strain to form long chains of cells that would score as a single $\mathrm{CFU}$ in plate counts. Oxidative stress may also limit colony formation of still-viable cells of $B$. simplex (10). B. simplex strain $03 \mathrm{WN} 13$ and $P$. agglomerans strain 10IL31 ranked first and second of the six antagonists studied in overall $\mathrm{RPI}_{\mathrm{Eff}, \mathrm{Kin}}$, respectively, showing the consistency between ranking of RPI $\mathrm{Eff}_{\text {and }}$ RPI $\mathrm{Kin}_{\text {(Ta- }}$ ble 5). Variability in growth kinetics for the strains of Bacillus tested in this study had a large impact on the RPI values obtained for the various kinetic RPIs and contributed to the overall kinetic RPI values not being separable statistically. In similar ranking studies using exclusively gram-negative bacteria, kinetic performance was more consistent between the kinetic parameters measured and, as a result, overall kinetic performance means frequently differed significantly (31).

Despite a lack of statistical separation of the overall RPI $\mathrm{Eff,Kin}_{\mathrm{K}}$ values determined for the six novel biological control strains identified in the current study, the ranks of strains obtained by the RPI procedure are useful as a logically sound method for considering on which strains to concentrate commercial development efforts and as a method for addressing which strain is the next best candidate to consider. If, in the course of precommercial product development, an altered medium is preferred for strain production or the conditions under which strain are to be used change considerably, then it should be understood that the commercial ranking obtained for the putative antagonists in this study is subject to recalculation to meet the specific need of the producer of the product. The commercial ranking procedure employed in this study does not consider the possibility that a prospective producer or user would prefer a dried biological control product. Drying economics, the comparative survival rate of dried isolates, and the disease suppressiveness of dried cells would all have a profound impact on the ranking of these strains but could also be incorporated into an RPIbased ranking procedure. Additionally, kinetic parameters different than those used here could be taken into account as alternative approaches for the economic analysis of the production process. Giving additional weight to those kinetic parameters considered most critical to a specific commercial fermenter when calculating and ranking isolate RPIs could also enhance the utility of the final rankings determined. Evaluation of software such as SuperPro Designer (Itelligen, Inc., Scotch Plains, NY), which enables users to model and predict the costs of industrial production processes, could be useful for estimating the importance of the effect of differing kinetic values on the rankings of the development potential of biocontrol agents and associated industrial process costs.

Table 6. Use of relative performance indices (RPIs) to accomplish a twodimensional assessment of isolate commercial potential based on the efficacy and growth kinetics of cells produced in liquid culture

\begin{tabular}{|c|c|c|c|c|}
\hline Strain & RPI $_{\text {Eff }}{ }^{w}$ & $\begin{array}{l}\text { Overall } \\
\text { RPI }_{\text {Kin }} \times\end{array}$ & $\begin{array}{c}\text { Overall } \\
\text { RPI }_{\text {Eff,Kin }}{ }^{\text {y }}\end{array}$ & $\mathrm{CPG}^{\mathrm{z}}$ \\
\hline 03WN13 & 51.0 (3) A & 64.1 (1) A & $57.6(1)$ & A \\
\hline 03WN23 & 49.1 (4) A & 52.8 (3) A & $50.9(3)$ & A \\
\hline 03WN25 & 52.1 (1) A & 49.1 (5) A & $50.6(4)$ & A \\
\hline 10IL21 & 47.9 (6) A & 35.9 (6) A & $41.9(6)$ & A \\
\hline 10IL31 & $51.4(2) \mathrm{A}$ & 53.5 (2) A & $52.4(2)$ & A \\
\hline 13IL01 & $48.4(5) \mathrm{A}$ & 49.2 (4) A & $48.8(5)$ & $\mathrm{A}$ \\
\hline
\end{tabular}

${ }^{\mathrm{w}} \mathrm{RPI}$ values for efficacy.

${ }^{\mathrm{x}} \mathrm{RPI}$ values for kinetics.

y RPI when considering both efficacy and kinetics.

${ }^{\mathrm{z}}$ Commercial potential groupings (CPGs) were determined by forming a dataset composed of RPI ${ }_{\text {Eff }}$ and $\mathrm{RPI}_{\mathrm{Kin}}$ data for each strain and subjecting the data to analysis of variance and mean separation using Fisher's protected least significant difference $(P \leq 0.05)$. Means not sharing a common letter belong to different commercial potential groups. 
An important but overlooked step regarding designing protocols for discovering biocontrol agents is to insure that selected strains are amenable to liquid culture production and efficacious when produced in this manner. Antagonists of pink rot in the current study were isolated from biologically based, suppressive soil extracts and then subjected to this two-dimensional method of ranking biocontrol agent potential. The top strains identified warrant further investigation of their ability to control pink rot of potato using increased dosages in a small-pilot storage trial where conditions closely emulate those under which the strains would have to perform in field use. Tests integrating the use of these strains and active fungicides are also needed and may allow a reduction in the amount of fungicide needed to suppress pink rot $(2,20)$.

\section{Acknowledgments}

We thank A. Phibbs, Department of Agriculture, Trade and Consumer Protection, Madison, WI; staff of Northwest Agricultural Products, Inc., Pasco, WA; S. Duval, R. Holloway, and S. Vaughn of NCAUR, United States Department of Agriculture-Agricultural Research Service (USDA-ARS), Peoria, IL for their assistance in obtaining soil samples that were assayed for pink rot suppressiveness in this study; H. Kline (NCAUR, USDA-ARS) for technical assistance in obtaining DNA sequence data; and M. Hammar for her assistance in preparing the figure.

\section{Literature Cited}

1. Adiyaman-Koltuksuz, T. 2007. Optimization of large scale production of some antagonistic bacterial formulation. Ph.D. dissertation, University of Ege, Department of Biotechnology, zmir, Turkey.

2. Al-Mughrabi, K. I., Peters, R. D., Platt, H. W., Moreau, G., Vikram, A., Poirier, R., and MacDonald, I. 2007. In-furrow applications of metalaxyl and phosphite for control of pink rot (Phytophthora erythroseptica) of potato in New Brunswick, Canada. Plant Dis. 91:305-1309.

3. Atallah, Z. K., and Stevenson, W. R. 2006. A methodology to detect and quantify five pathogens causing potato tuber decay using real-time quantitative polymerase chain reaction. Phytopathology 96:1037-1045.

4. Benson, J. H., Geary, B., Miller, J. S., Jolley, V. D., Hopkins, B. G., and Stevens, M. R. 2009. Phytophthora erythroseptica (pink rot) development in Russet Norkotah potato grown in buffered hydroponic solutions I. Calcium nutrition effects. Am. J. Potato Res. 86:466-471.

5. Cook, R. J. 1991. Twenty-Five Years of Progress Towards Biological Control Impact AgBioBusiness. CAB International, Oxon, UK.

6. Cook, R. J. 1993. Making greater use of introduced microorganism for biological control of plant pathogens. Annu. Rev. Phytopathol. 31:53-80.

7. Costa, E., Teixidó, N., Usall, J., Atarés, E., and Viñas, I. 2001. Production of the biocontrol agent Pantoea agglomerans strain CPA-2 using commercial products and by-products. Appl. Microbiol. Biotechnol. 56:367-371.

8. Drobniewski, F. A. 1993. Bacillus cereus and related species. Clin. Microbiol. Rev. 6:324-338.

9. Elson, M. K, Schisler, D. A., and Bothast, R. J. 1997. Selection of microorganisms for biological control of silver scurf (Helminthosporium solani) of potato tubers. Plant Dis. 81:647-652.

10. Gomaa, O. M., and Azab, K. S. 2007. Role of calcium carbonate in protecting the colony forming ability of Bacillus simplex TWW-04 exposed to oxidative stress. Adv. Biol. Res. 1:49-55.

11. Hollywood, J.C. 2008. Biological control of late blight of potatoes: in vivo and in vitro evaluation of microbial antagonists against tuber blight. Ph.D. dissertation, University of London, Biology Department, London.

12. Hultberg, M., Alsberg, T., Khalil, S., and Alsanius, B. 2010. Suppression of disease in tomato infected by Pythium ultimum with a biosurfactant produced by Pseudomonas koreensis. Biocontrol 55:435-444.

13. Johnson, S. B. 2008. Post-harvest applications of phosphorous acid materials for control of Phytophthora infestans and Phytophthora erythroseptica on potatoes. Plant Pathol. 7:50-53.

14. Kimura M. 1980 A simple method for estimating evolutionary rates of base substitutions through comparative studies of nucleotide sequences. J. Mol. Evol. 16:111-120.

15. Kotan, R., Sahin, F., Erkol, D., and Cafer, E. 2009. Biological control of the potato dry rot caused by Fusarium species using PGPR strains. Biol. Control 50:194-198.

16. Lane, D. J. 1991. 16S/23S rRNA sequencing. Pages 115-175 in: Nucleic Acid Techniques in Bacterial Systematics. E. Stackebrandt and M. Goodfellow, eds. Wiley, Chichester, UK.

17. Lioussanne, L., Perreault, F., Jolicoeur, M., and St. Arnaud, M. 2010. The bacterial community of tomato rhizosphere is modified by inoculation with arbuscular mycorrhizal fungi but unaffected by soil enrichment with my- corrhizal root exudates or inoculation with Phytophthora nicotianae. Soil Biol. Biochem. 42:473-483.

18. Manso, T., Nunes, C., Raposo, S., and Lima-Costa, M. E. 2009. Production of the biocontrol agent Pantoea agglomerans PBC-1 in a stirred tank reactor by batch and fed-batch cultures. World J. Microbiol. Biotechnol. 26:725735 .

19. Marchesi, J. R., Sato, T., Weightman, A. J., Martin, T. A., Fry, J. C., Hiom, S. J., Dymock, D., and Wade, W. G. 1998. Design and evaluation of useful bacterium-specific PCR primers that amplify genes coding for bacterial $16 \mathrm{~S}$ rRNA. Appl. Environ. Microbiol. 64:795-799.

20. Miller, J. S., Olsen, N., Woodell, L., Porter, L. D., and Clayson, S. 2006 Post harvest applications of zoxamide and phosphite for control of potato tuber rots caused by oomycetes at harvest. Am. J. Potato Res. 83:269-278.

21. Mills, A. A. S., Platt, H. W., and Hurta, R. A. R. 2005. Salt compounds as control agents of late blight and pink rot of potatoes in storage. Can. J. Plant Pathol. 27:204-209.

22. Powell, K. A. 1992. Biocontrol product fermentation, formulation and marketing. Pages 381-387 in: Biological Control of Plant Diseases, Progress and Challenges for the Future. E. C. Tjamos, G. C. Papavizas, and R. J. Cook, eds. Nato ASI Series, Plenum Press, New York.

23. Rooney, A. P., Price, N. P. J., Ehrhardt, C., Swezey, J. L., and Bannan, J. D. 2009. Phylogeny and molecular taxonomy of the Bacillus subtilis species complex and description of Bacillus subtilis subsp. inaquosorum subsp. nov. Int. J. Syst. Evol. Microbiol. 59:2429-2436.

24. Rooney, A. P., Swezey, J. L., Wicklow, D. T., and McAtees, M. J. 2005 Bacterial species diversity in cigarettes linked to an investigation of severe pneumonitis in U.S. military personnel deployed in operation Iraqi freedom. Curr. Microbiol. 51:46-52.

25. Salas, B., Secor, G. A., Taylor, R. J., and Gudmestad, N. C. 2003. Assessment of resistance of tubers of potato cultivars to Phytophthora erythroseptica and Pythium ultimum. Plant Dis. 87:91-97.

26. Salas, B., Stack, R. W., Secor, G. A., and Gudmestad, N. C. 2000. The effect of wounding, temperature, and inoculum on the development of pink rot of potatoes caused by Phytophthora erythroseptica. Plant Dis. 84:13271333.

27. Schisler, D. A., and Slininger, P. J. 1994. Selection and performance of bacterial strains for biologically controlling Fusarium dry rot of potatoes incited by Gibberella pulicaris . Plant Dis. 78:251-255.

28. Schisler, D. A., Slininger, P. J., Hanson, L. E., and Loria, R. 2000. Potato cultivar, pathogen isolate and antagonist cultivation medium influence the efficacy and ranking of bacterial antagonists of Fusarium dry rot. Biocontrol Sci. Technol. 10:267-279.

29. Schisler, D. A., Slininger, P. J., Miller, J. S., Woodell, L. K., Clayson, S., and Olsen, N. L. 2009. Bacterial antagonists, zoospore inoculum retention time and potato cultivar influence pink rot disease development. Am. J. Potato Res. 86:102-111.

30. Secor, G. A., and Gudmestad, N. C. 1999. Managing fungal diseases of potato. Can. J. Plant Pathol. 21:213-221.

31. Slininger, P. J., Schisler, D. A., and Bothast, R. J. 1994. Two-dimensional liquid culture focusing: a method of selecting commercially promising microbial isolates with demonstrated biological control capability. Pages 2932 in: Improving Plant Productivity with Rhizosphere Bacteria. M. H. Ryder, P. M. Stephens, and G. D. Bowen, eds. The 3rd Int. Workshop Plant Growth-Promoting Rhizobacteria. CSIRO Division of Soils, Glen Osmond, South Australia.

32. Slininger, P. J., Schisler, D. A., Ericsson, L. D., Brandt, T. L., Frazier, M. J. Woodell, L. K., Olsen, N. L., and Kleinkopf, G. E. 2007. Biological control of post-harvest late blight of potatoes. Biocontrol Sci. Technol. 17:647-663.

33. Stockwell, V. O., Johnson, K. B., Sugar, D., and Loper, J. E. 2002. Antibiosis contributes to biological control of fireblight by Pantoea agglomerans strain Eh252 in orchards. Phytopathology 92:1202-1209.

34. Tamura, K., Dudley, J. Nei, M., and Kumar, S. 2007. MEGA4: Molecular Evolutionary Genetics Analysis (MEGA) software version 4.0. Mol. Biol. Evol. 24:1596-1599.

35. Taylor, R. J., Pasche, J. S., and Gudmestad, N. C. 2006. Biological significance of mefenoxam resistance in Phytophthora erythroseptica and its implications for the management of pink rot of potato. Plant Dis. 90:927-934.

36. Thompson, J. D., Gibson, T. J., Plewniak, F., Jeanmougin, F., and Higgins, D. G. 1997. The CLUSTAL-X windows interface: flexible strategies for multiple sequence alignment aided by quality analysis tools. Nucleic Acids Res. 25:4876-4882.

37. Wang, L. T., Lee, F. L., Tai, C. J., Yokota, A., and Kuo, H. P. 2007. Reclassification of Bacillus axarquiensis Ruiz-Garcia et al. 2005 and Bacillus malacitensis Ruiz-Garcia et al. 2005 as later heterotypic synonyms of Bacillus mojavensis Roberts et al. 1994. Int. J. Syst. Evol. Microbiol. 57:1663-1667.

38. Wharton, P., and Kirk, W. 2007. Pink rot. Ext. Bull. E-2993, Mich. Potato Dis. Michigan State University, East Lansing. Available online. 